\title{
Ensino remoto de emergência no período da pandemia: o uso da tecnologia e inovação nas instituições de Ensino Superior
}

\author{
Remote emergency education in the pandemic period: the use of technology and innovation in
}

\author{
Higher Education institutions
}

Educación de emergencia a distancia en el período de pandemia: el uso de la tecnología y la

innovación en las instituciones de Educación Superior

Recebido: 26/01/2022 | Revisado: 31/01/2022 |Aceito: 06/02/2022 | Publicado: 07/02/2022

\author{
Bruno Leandro Martins \\ ORCID: https://orcid.org/0000-0002-2651-1189 \\ Universidade Federal do Tocantins, Brasil \\ E-mail: profissionalb.martins@gmail.com
}

\begin{abstract}
Resumo
Introdução: a pandemia, devido a sua gravidade e quantidade vítimas no mundo, tornou-se um tema atual e muito debatido em conteúdos científicos, visto que suas consequências e impactos atingiram diversos setores. Com o avanço do vírus da Covid-19, as medidas restritivas tiveram que ser mais rígidas, o que impactou no fechamento de serviços não essências, no qual ressaltam-se as escolas e universidades que tiveram que buscar alternativas de ensino diante o isolamento e toda turbulência da pandemia. Diante desse contexto, a maioria das instituições de ensino superior utilizaram o método de aulas remotas para não interromper o aprendizado. Objetivo: mostrar as mudanças e inovações realizadas nas universidades para agregar o ensino remoto emergencial. Metodologia: Foi realizada uma pesquisa bibliográfica no qual a coleta de dados ocorreu em artigos científicos, livros revista, anuais e periódicos. Desenvolvimento: No período da pandemia é evidente a utilização do meio tecnológico para garantir o ensino, no qual ferramentas como: as vídeo aulas, palestras online, Microlearning, Ambientes Virtuais de Aprendizagem, são os destaques dessa modalidade, por já ser um dos métodos aplicados no ensino à distância. Discussão: as inovações realizadas no período de pandemia podem ser consideradas um diferencial para o estudo dos universitários, com a capacidade de interação pelos smartphones, que por sua vez, favorecem e facilitam o acesso aos conteúdos digitais. Conclusão: $\mathrm{O}$ investimento na tecnologia e inovações são essenciais para o crescimento do método de ensino à distância, o que facilitou o acesso na transição para o período de ensino remoto emergencial.
\end{abstract}

Palavras-chave: Covid-19; Tecnologia; Ensino à distância.

\begin{abstract}
Introduction: the pandemic, due to its severity and number of victims in the world, has become a current topic and much debated in scientific content, since its consequences and impacts have reached several sectors. With the advance of the Covid-19 virus, restrictive measures had to be stricter, which had an impact on the closing of non-essential services, in which schools and universities that had to seek teaching alternatives in the face of isolation and all pandemic turmoil. Given this context, most higher education institutions used the method of remote classes so as not to interrupt learning. Objective: to show the changes and innovations carried out in universities to add emergency remote teaching. Methodology: A bibliographic research was carried out in which data collection took place in scientific articles, books, magazines, annuals and periodicals. Development: In the period of the pandemic, the use of the technological means to guarantee teaching is evident, in which tools such as: video classes, online lectures, Microlearning, Virtual Learning Environments, are the highlights of this modality, as it is already one of the methods applied in distance learning. Discussion: the innovations carried out during the pandemic period can be considered a differential for the study of university students, with the ability to interact through smartphones, which in turn, favor and facilitate access to digital content. Conclusion: Investment in technology and innovations are essential for the growth of the distance learning method, which facilitated access in the transition to the emergency remote teaching period.
\end{abstract}

Keywords: Covid-19; Technology; Distance learning.

\section{Resumen}

Introducción: la pandemia, por su gravedad y número de víctimas en el mundo, se ha convertido en un tema actual y muy debatido en el contenido científico, ya que sus consecuencias e impactos han llegado a varios sectores. Con el avance del virus Covid-19, las medidas restrictivas debieron ser más estrictas, lo que repercutió en el cierre de 
servicios no esenciales, en los que se encontraban escuelas y universidades que debieron buscar alternativas docentes ante el aislamiento y toda la conmoción por la pandemia. Ante este contexto, la mayoría de las instituciones de educación superior utilizaron el método de clases a distancia para no interrumpir el aprendizaje. Objetivo: mostrar los cambios e innovaciones llevados a cabo en las universidades para sumar la docencia a distancia de emergencia. Metodología: Se realizó una investigación bibliográfica en la que la recolección de datos se realizó en artículos científicos, libros, revistas, anuarios y periódicos. Desarrollo: En el período de la pandemia se evidencia el uso de los medios tecnológicos para garantizar la enseñanza, en la que herramientas como: videoclases, conferencias en línea, Microaprendizaje, Entornos Virtuales de Aprendizaje, son los destaques de esta modalidad, como ya lo es. uno de los métodos aplicados en la educación a distancia. Discusión: las innovaciones realizadas durante el período de la pandemia pueden considerarse un diferencial para el estudio de los estudiantes universitarios, con la capacidad de interactuar a través de los teléfonos inteligentes, que a su vez, favorecen y facilitan el acceso a los contenidos digitales. Conclusión: La inversión en tecnología e innovaciones son fundamentales para el crecimiento de la modalidad de enseñanza a distancia, lo que facilitó el acceso en la transición al período de enseñanza a distancia de emergencia.

Palabras clave: Covid-19; Tecnología; Educación a distancia.

\section{Introdução}

O presente estudo possui como temática, as mudanças da educação no período de pandemia, onde foi desenvolvido um estudo sobre o método de Ensino Remoto Emergencial (ERE), evidenciando as ferramentas de inovação e os meios tecnológicos que facilitaram essa forma de aprendizagem alternativa ao meio presencial.

Um novo vírus, originado na China no fim do ano de 2019, identificado como coronavírus e cientificamente por Corona Vírus Disease 2019 (Covid-19), causou mudanças no cenário do mundo. Isso ocorreu devido à facilidade de contágio e a sua elevada taxa de mortalidade. Diante desse fato a Organização Mundial da Saúde (OMS), declarou estado de pandemia global a partir de março de 2020. (Ministério da Saúde, 2021)

Com a pandemia, os hábitos e costumes da população foram alterados, medidas restritivas e distanciamento social foram determinados Ministério da Saúde (MS), para a segurança das pessoas e redução de contágio do vírus. Com essas precauções lojas, comércios, escolas e universidades suspenderam suas atividades presenciais (Pacheco, 2020)

Apesar das restrições, a produtividade dos meios comercias e educacionais não podiam ser interrompidas completamente, assim após alguns meses de adaptação foram adaptadas às formas de trabalho e estudo remoto. Em que, o uso das tecnologias e meios digitais são primordiais, principalmente na educação (Arruda \& Siqueira, 2021).

Os impactos diante da pandemia foram significativos, na saúde e educação global. Em dados do Ministério da Educação (MEC), foi apontado que 1,5 bilhões de estudantes tiveram as aulas interrompidas, o que equivale a $90 \%$ dos alunos de todo o mundo. As escolas de ensino fundamental foram as mais afetadas, diante da recomendação para a Instituição de Ensino Superior (IES) substituir as aulas presenciais pelo ensino remoto, enquanto o status de pandemia oferecer risco a saúde. Com essa nova demanda o consumo de tecnologia cresceu cerca de 35\% nesse período (Arruda \& Siqueira, 2021).

As aulas remotas não são um método de ensino, é uma medida provisória baseado no estilo do Ensino à Distância (EAD), para suporte dos estudantes que possuíam as medidas de atividades acadêmicas presenciais ou semipresenciais, e assim os discentes não serem prejudicados pela falta de conteúdo no período da pandemia (Avelino \& Mendes, 2020).

Diante da contextualização o estudo parte do seguinte questionamento: quais mudanças e inovações tecnológicas foram realizadas para atender a demanda do ERE para as IES na pandemia?

A hipótese inicial do estudo refere-se que investir em tecnologia é de grande importância para as IES em qualquer período. Mesmo diante a pandemia que ocorreu de forma imprevisível, as modificações possibilitaram o aprendizado de forma remota. Onde as adaptações do modo de EAD foram essenciais para os recursos tecnológicos em proporções elevadas.

A realização desse estudo, se dá pela justificativa da forma com que a educação sofreu modificações, principalmente no cenário atual de pandemia. Manter uma ferramenta como a internet pode facilitar e mediar o contato entre acadêmico e docente. Além de intermediar a diferença entre o ERE e EAD. 
Reforçando a ideia acima, os benefícios que o EAD trouxe para a educação e da informação, foram elevados no período de pandemia para adaptar o ERE. Evidenciando as possíveis consequências no âmbito do acesso e disponibilidade das IES para que o ensino não fosse interrompido. A proposta tem base na evolução de tecnologias, tendo como consequência de imprecisão e as suas possíveis vulnerabilidades diante as inovações.

O presente estudo foi elaborado com o objetivo geral de verificar o que a literatura trás diante as mudanças e inovações realizadas nas IES no período de pandemia.

E como objetivos específicos são: a) mostrar os aspectos relacionados ao período da pandemia com ensino; b) relacionar o ERE com a pandemia; c) analisar o que a literatura traz da relação EAD e O ERE.

\section{Metodologia}

A metodologia para realização da pesquisa foi através de revisão literária do tipo integrativa cuja finalidade foi sintetizar resultados obtidos em pesquisas sobre o tema proposto aplicando critérios metodológicos para elaborar a análise de forma ordenada e abrangente. O método desta pesquisa é a descrição e pesquisa qualitativa. Para assegurar o nível de evidência, desenvolveu-se o levantamento bibliográfico em livros, artigos científicos, revista, sites e dissertações anuais e periódicos, como método de pesquisa do tema proposto foram selecionadas as seguintes palavras-chave: Covid-19; Tecnologia; Ensino à Distância.

\section{Desenvolvimento}

\subsection{Aspectos da Pandemia}

A Covid-19, é uma mutação do coronavírus, que surgiu na China e ganhado proporção em todo o mundo, é de fácil contágio, inicialmente possui sintomas similares a de uma gripe com evoluções para: febre, falta de ar e tosse. Em algumas pessoas o vírus pode comprometer a capacidade pulmonar e acentuar sintomas de comorbidades. Cerca de $8 \%$ das pessoas que contraem o covid-19 necessitam de atendimentos mais rigorosos como as Unidades de Terapia Intensiva (UTI), no qual parte dessa população não resiste e vai a óbito (Arruda \& Siqueira, 2021).

O mundo está em status de pandemia, o que levou a sociedade atual, além de produzir, consumir conteúdos digitais. Nesse período a maioria das pessoas evitam sair de suas casas, no qual ambientes considerados não essenciais foram fechados como as escolas, faculdades, cinemas, estádios de futebol, teatros, bares, restaurantes entre outros. Assim, o meio encontrado por muitas pessoas para passar esse período de isolamento foi o meio digital e mídias de audiovisual. A utilização desse meio cresceu em torno de 35\% conforme a Associação Nacional dos Especialista em Política Pública e Gestão Governamentais (ANESP) (Oliveira \& Souza, 2020).

Em uma análise do trajeto da raça humana, desde o início dos tempos, identificações das capacidades de criar ferramentas para estabelecer habilidades e enfrentar o desconhecido são de fato os maiores marcos da história. Todavia a técnica sem uma necessidade de aplicação não se mostra útil. O que leva a maioria das criações ser desenvolvidas para atender necessidades que são de fato utilizáveis para o período (Kussler, 2015).

Diante do contexto atual de pandemia não prevista, nota-se uma mudança nas prioridades de planejamentos e programações, frente à decorrência do vírus, contando com a superação, redução do fluxo social e quebra nas atividades básicas que mantêm uma sociedade ativa (Kussler, 2015).

$\mathrm{O}$ vírus que possui origem asiática, de fato, modificou o cenário mundial, devido a sua facilidade de contágio, através de partículas, como secreção nasal e saliva. E como ele se espalha de forma rápida, a solução para evitar esse contágio foi através de proteção da área de nariz e boca com a utilização de máscaras, juntamente com o distanciamento social (Arruda \& Siqueira, 2021). 
O distanciamento revelou algumas categorias de aspectos para modificar a interação social, como o aumento da utilização de webconferências possibilitando o contato mesmo a distância. E o uso dessa tecnologia facilitou praticas para diversos público e empresas, como as escolas, reuniões de trabalho, faculdades e afins (Kussler, 2015).

A necessidade de manter a funcionalidade das atividades no período da pandemia fizeram com que empresas como Zoom, Hangout Google Meet, Messenger Rooms, Skype, YouTube, Facebook, aumentassem os seus suportes para suprir a crescente demanda. $\mathrm{O}$ avanço das tecnologias digitais de informação possibilitou a criação de ferramentas que podem ser utilizadas pelos usuários e criando uma forma de garantir o trabalho de forma remota (Rocha, 2021).

Os trabalhos realizados remotamente, começaram no período de 1970, os termos foram adaptados com nomenclaturas distintas e convergentes do mesmo propósito de teleatendimento na linguagem inglesa, onde foram iniciadas as definições os termos mais comuns são: telecommuting, telework e home office, essa forma de trabalho mudou o conceito de ensinar de alguns docentes. Com isso o método de trabalho remoto foi elevado significativamente comparado ao mesmo período antecessor ao da pandemia (Arruda \& Siqueira, 2021).

Com a mudança do ensino para o modelo remoto, adaptações tiveram que ser realizadas, que serão abordados no tópico a seguir.

\subsection{Pandemia e o ERE}

Os impactos diante da pandemia foram significativos, não só as pessoas que contraíram, mas todo o mundo, em dados do MEC, foi apontado que 1,5 bilhões de estudantes tiveram suas aulas interrompidas, o que é equivalente a 90\% dos alunos de todo o mundo. As escolas de ensino fundamental foram as mais afetadas, diante da recomendação para as IES substituir as aulas presenciais por ensino remoto, enquanto o vírus oferecer risco a saúde pública (Arruda E Siqueira, 2021).

Assim foi determinado no país a portaria ${ }^{\circ} 343.17 .03 .2020$, sinalizando que devido ao Covid-19, determina-se que o ensino presencial será ofertado através das aulas remotas, enquanto o status de pandemia for vigente, no período de 30 dias podendo haver prorrogação (Brasil, 2020).

Diante ao ERE, mudanças no conceito de estudo presenciais foram realizados, uma forma de ensino alternativo para incluir as atividades acadêmicas no período de pandemia. Com a regulação para aulas remotas, os recursos digitais utilizados no método de EAD, contribuíram para a possibilidade desse meio emergencial de ensino (Rodrigues, 2020).

Os cursos que mais foram prejudicados com a troca emergencial do método presencial por um modelo EAD, foram os da área de saúde, isso ocorreu devido à dificuldade do conhecimento prático e o contato com o público no período de estágio. Outro fator que foi prejudicial aos alunos com à troca foi o atraso dos formandos que precisavam cumprir a carga horaria prática estabelecidas pelas IES (Hodges et al., 2020).

Com essa nova demanda de todos os cursos precisarem aderir ao modelo à distância, o consumo de tecnologia cresceu. A maioria das IES aderiram ao modelo de ensino remoto, através de aulas online, novas plataformas foram criadas e adaptadas. Fazendo com que professores e alunos se atualizassem e adaptassem a essa realidade (Avelino \& Mendes, 2020).

Vale ressaltar que não foi uma escolha, ou uma votação o ERE, mas sim a alternativa mais viável e prudente diante do vírus e respeitar o distanciamento social. O método de EAD, já existia, no entanto, não se aplicava a todos os cursos. Como ocorre atualmente, com essa medida, os softwares tiveram que ser atualizados para suportar o aumento significativo dos alunos e professores. A maior dificuldade encontrada para ser possível essa transição de aulas presenciais para aulas remotas foi a utilização das plataformas, destacam-se as pessoas com mais idade que não possuía interação constante com os meios digitais (Hodges et al., 2020).

Em meio ao novo regime, as disciplinas teóricas e partes das práticas passaram as ser realizadas remotamente, através de plataformas digitais, o que possibilitou o contato entre docentes e discentes. Além dos Ambientes Virtuais de Aprendizagem 
(AVA), redes sociais como WhatsApp, telegram e facebook, contribuíram para facilitar e intermediar o acesso ao estudo (Valente et al., 2020)

Com a implantação do ERE, foram adotadas duas medidas de ensino às sincrônicas e assincrônicas descritas no Quadro 1 a seguir:

Quadro 1 - Conceito e definição das medidas de ensino EAD e ERE.

\begin{tabular}{|l|l|}
\hline Conceito & Definição \\
\hline Síncrona & $\begin{array}{l}\text { são aulas em que é necessária a participação do aluno e professor no mesmo instante e no mesmo ambiente nesse } \\
\text { caso, virtual. Assim sendo, ambos devem se conectar no mesmo momento e interagir entre si de alguma forma } \\
\text { para concluírem o objetivo da aula. }\end{array}$ \\
\hline Assíncrona & $\begin{array}{l}\text { são aulas consideradas desconectadas do momento real e/ou atual, ou seja, não é necessário que os alunos e } \\
\text { professores estejam conectados ao mesmo tempo para que as tarefas sejam concluídas e o aprendizado seja } \\
\text { adequado. }\end{array}$ \\
\hline
\end{tabular}

Fonte: Valente (2020).

A aplicação do ERE aos cursos que seriam presenciais segue para os setores educacionais na maioria das vezes de forma síncronas o que leva ao padrão do ensino na sala de aula, com data e hora predeterminadas, ou seguindo o quadro de horários das aulas presenciais. Diante desse fato mesmo diante da pandemia elevou a quantidade de alunos que se matricularam em cursos com modalidade EAD, o gráfico a seguir mostra que a escolha por esse meio de ensino já se mostrava crescente, antes do período pandêmico (Santos et al., 2020).

Gráfico 1 - Relação de matrículas no método presencial e EAD.

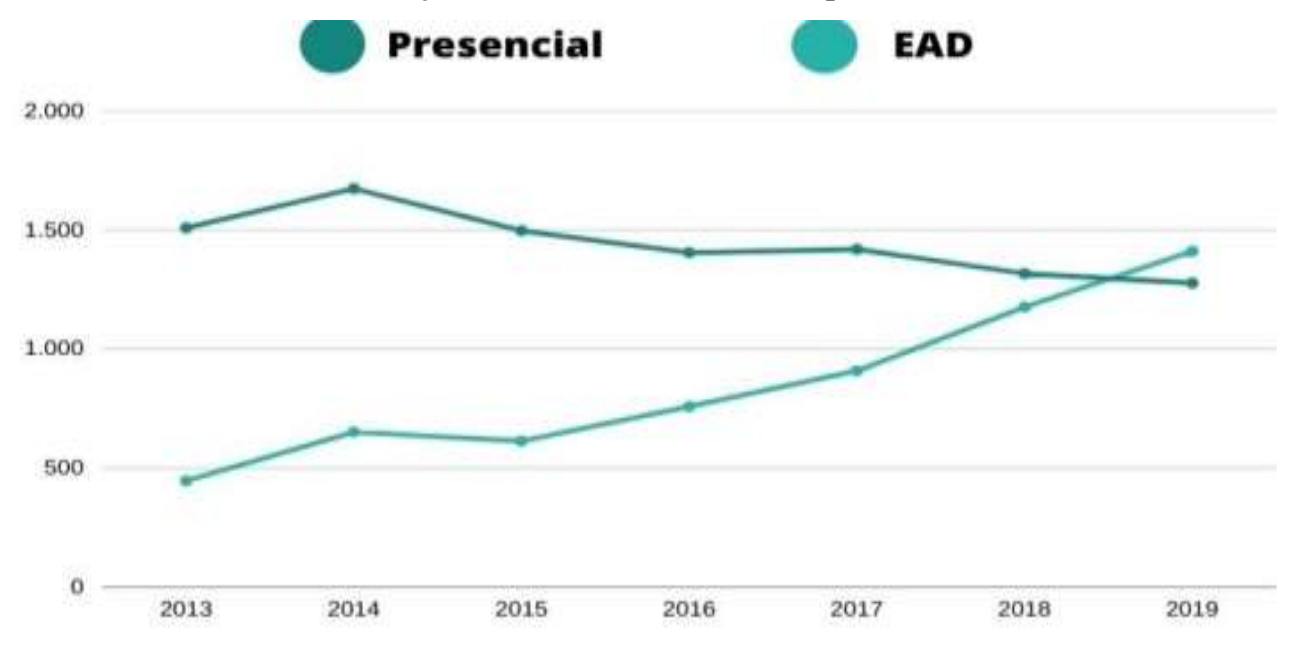

Fonte: Atmã educar (produção uol) (2020).

A modalidade do EAD mostrou que possui menos evasão e desistência pelos alunos comparando ao método presencial, justifica-se pelo fato de conciliação entre a vida pessoal, trabalho e o estudo. E muitos alunos que participaram do ERE podem levar um tempo para voltar aos métodos tradicionais. O que pode fazer com que novos alunos optem de forma significativa ao EAD (Camacho, 2020).

As IES particulares se adaptaram mais rapidamente que as instituições públicas, devido à utilização das plataformas e aos custos extras com suporte que tiveram que ser implantadas, com exceções das universidades que ofertavam somente a forma de ensino presencial, que mostraram dificuldades em adaptar o método de ensino ao ERE (Rocha, 2021) 
Apesar do viés de pandemia, com a crise que atingiu diversos fatores econômicos, o estilo de ERE atraiu a visão para o EAD positivamente, novas matrículas e pessoas passaram a possuir conhecimento sobre o método e inclui-los as suas rotinas, fazendo com que pesquisadores afirmem que o conceito de estudar a distância ainda cresça no pós-pandemia (Rocha, 2021).

Com o distanciamento social, a tecnologia utilizada para realizar chamadas por vídeos já eram ferramentas utilizadas por grande parte da população, mas quando essa função se tornou um meio de aproximação social, familiar, trabalhista e educacional tiveram que realizar ajuste para atender em larga escala, aperfeiçoando e acrescentar a capacidade de reproduzir de forma simultânea para várias pessoas (Rocha, 2021).

\subsection{Uso da Tecnologia no EAD e a relação com o ERE}

O método de EAD, foi implementado em meado do século 19 essa forma de ensino era realizada através de correspondência, entre as unidades de ensino e os alunos. O que levava o processo de aprendizagem ser mais longos, devido ao tempo que levava para a entrega de matérias educacionais (Kussler, 2015).

Com a chegada da internet a capacidade de conhecimento a distância, aumentaram de forma significativa, a possibilidade de ter acesso à informação e realizar pesquisas práticas e rápida mudou o que se conhecia por EAD. O que elevou a procura pelo ensino e possibilitou o acesso a mulheres e pessoas mais jovens que buscam o aprendizado (Rocha, 2021)

A tecnologia da internet favoreceu e flexibilizou os métodos de ensino, para várias categorias de situações, como pessoas do meio rural ou que moral mais afastados do centro das cidades, também melhorou o contato de quem trabalha em horários que não são fixos ou com jornadas trabalhistas muito longas (Churkin, 2020).

No início da pandemia as quedas e instabilidades de suporte das plataformas eram constantes, o que relatado como transtorno pelos usuários, isso mudou tudo com relação ao que se conhecia como aprender e a ensinar. As mudanças e atualizações ainda estão sendo realizadas e adaptadas para melhor atender os usuários em todo o mundo (Arruda \& Siqueira, 2021).

O ERE está ligado às novas formas de tecnologia e inovação, e contextualizando novas formas de interagir entre o ensino e o estudante. As modalidades e cursos ofertados nesse período permitiram ao estudante autonomia para atender diversas demandas impostas no dia a dia. Os benefícios inclusos em estudar remotamente, são ter acesso ao conteúdo e as aulas em ambientes seguros. Os materias complementares estão sempre a disposição podendo ser acessados de forma online, ou com ferramentas que realize o download do material e permita a utilização offline. As ferramentas mais utilizadas para facilitar o contato serão descritas no Quadro 2 a seguir (Bezerra, 2021). 
Quadro 2 - Métodos de ensino através do digital.

\begin{tabular}{|c|l|}
\hline \multicolumn{1}{|c|}{ Método } & Definição \\
\hline Videoaulas & $\begin{array}{l}\text { Para apresentar os conteúdos, a gravação de aulas para transmissão online é um dos formatos preferidos. } \\
\text { Ela possibilita ministrar uma aula e apresentar slides interativos, favorecendo a aprendizagem } \\
\text { audiovisual, que é bastante similar à maneira presencial. }\end{array}$ \\
\hline Palestras online & $\begin{array}{l}\text { A disponibilização de palestras online e ao vivo propiciam às plataformas digitais uma complementação } \\
\text { interessante aos estudos. Elas podem tratar de diversos assuntos e contar com a participação de } \\
\text { convidados com conhecimentos avançados dos temas, sendo um recurso que atrai a atenção e atinge, } \\
\text { mais facilmente, um maior número de estudantes. }\end{array}$ \\
\hline \multicolumn{1}{|c|}{ Microlearning } & $\begin{array}{l}\text { Esse método de ensino tem como objetivo dividir um conteúdo mais profundo em pequenas e } \\
\text { concentradas partes, tendo diversos formatos de apresentação. Geralmente, os alunos aprendem em um } \\
\text { curto espaço de tempo por meio de vídeos, animaçóes, podcasts, infográficos, entre outros. }\end{array}$ \\
\hline $\begin{array}{l}\text { Ambientes } \\
\text { Virtuais } \\
\text { Aprendizagem }\end{array}$ & $\begin{array}{l}\text { Nos Ambientes Virtuais de Aprendizagem, o público tem acesso às aulas e atividades referentes a cada } \\
\text { assunto abordado no curso, sendo, portanto, a plataforma oficial de ensino. O AVA oferece uma } \\
\text { variedade de formatos, como fóruns interativos, questionários, vídeos e áudios. }\end{array}$ \\
\hline Biblioteca virtual & $\begin{array}{l}\text { Como qualquer outra Instituição de Ensino, também possibilita o acesso a uma variedade de recursos } \\
\text { bibliográficos, essenciais para a melhoria da experiência escolar. As bibliotecas virtuais, assim, servem } \\
\text { como um acervo online de livros, revistas e artigos científicos que complementarão o conhecimento dos } \\
\text { estudantes. }\end{array}$ \\
\hline
\end{tabular}

Fonte: Bezerra (2021).

Apesar dos métodos que já vinham sendo implementados ao longo dos anos citados no Quadro 1, a inovação da inteligência artificial, mostrou-se em evolução e evoluiu no período de pandemia, isso devido à demanda elevada para atendimento. Com esse método permite que as IES, analise o que está apresentando mais dificuldade de aprendizado dos alunos, criar projetos para suprir essa carência, o que no estudo presencial muitas vezes passaram despercebido, a tecnologia mostra em resultados a eficácia e o método, facilitando a forma de aprendizagem do aluno (Bezerra, 2021).

\section{Inovações e Tecnologia do Ensino Superior no Período de Pandemia}

Conforme mencionado anteriormente tem-se que a crise sanitária aumentou a vulnerabilidade da forma de estudo. Além da classe trabalhadora como professores e diretores das IES presenciais foram afetados pelo novo modelo, os alunos também, que por sua vez, foram pegos desprevenidos e tiveram que se adaptar e inovar diante a utilização da internet (Mesquita et al., 2014).

O ensino foi prejudicado referente à aplicação de provas, trabalhos, seminários dos cursos que possuíam a modalidade prática (Castaman \& Rodrigues, 2020). Churkin (2020) mostrou que apesar da dificuldade em aplicar critérios de teste de conhecimento, o ERE com a presença do professor em horário de aula e apresentações são mais efetivos do que a forma de aula gravada.

Outro ponto inovador foi a capacidade de ter acesso permanente as aulas gravadas, diferente do método tradicional do EAD que possuíam pouca ou nenhuma interação com o aluno (Camacho, 2020). Em concordância Churkin (2020), acrescenta que a forma de ERE reduziram a robotização das aulas gravadas e reproduzidas para um grande público. Com a interação de forma reduzida com pessoas conhecidas facilita a comunicação e o aprendizado.

Em contrapartida, os alunos do ensino fundamental e médio foram os mais afetados diante a pandemia, principalmente as redes públicas. O não preparo, a falta de interação dos alunos e pais com o meio digital se mostrou um dos fatores pelo fracasso de aplicação do método EAD nas escolas públicas, com evasão de 75\% dos alunos. Castaman e Rodrigues (2020) realizou uma comparação com o IES e destacou a importância de inserir o uso de inovações tecnológicas independente da forma de ensino. 
Outro ponto que se mostrou inovador foi a capacidade dos docentes de participar do modo de ensino remoto, visto que não houve nenhum tipo de preparação ou treinamento para utilizar os métodos de EAD (Avelino \& Mendes, 2020). Todavia, Martins (2020) afirma que diante dos fatos ressignificou o conceito de ensinar e ampliou o conhecido dos professores.

Santos (2020) destacou que ao menos $85 \%$ dos docentes já haviam tido contato com formas digitais de ensino como exemplo as apresentaç̃̃es por Datashow e a interação por notebook. No entanto o percentual foi de $76 \%$ dos professores que participaram do ERE, alguns docentes que participaram da pesquisa relataram dificuldade de adaptação, sobrecarga de trabalho e desempenhava outros papéis que dificultava o ERE.

Contudo, a maioria dos professores encontraram formas de passar o conhecimento para os alunos. A modelo de ensino síncrona foi a mais complicada de adaptação, devido a quedas, instabilidades de sistemas, falhas, microfonia entre outros problemas que foram identificados ao longo do período ERE, fizeram com que o os docentes e equipes técnicas se inovassem e utilizassem a tecnologia a favor do ensino, e assim passando o conteúdo aos discentes (Avelino; Mendes, 2020).

Há de se considerar que o celular no Brasil possui cerca de 300 milhões de usuários, um crescimento constante. Dentro dessa realidade, grande parte da população possui um aparelho móvel e está conectada, facilitando o acesso e levando o conhecimento a qualquer hora e em qualquer lugar (Castaman \& Rodrigues, 2020). A maioria das atualizações e inovações realizadas no período de pandemia foi para aparelhos moveis, por possuírem capacidades de performance muitas vezes inferior à de um computador empresas como Google, Microsoft, Zoom, entre outras, direcionaram suas ferramentas para melhorar a forma de interação dos aparelhos. Diante esse fato, tem-se que a forma com que o método EAD evoluiu no período de pandemia se deve pela capacidade de integrar os smartphones como meio de aprendizado móvel. (Martins, 2020)

Graças às políticas implementadas e à dinâmica favorável do EAD, cerca de $90 \%$ dos alunos das IES aderiram a estudar de remotamente. Dados contínuos do MEC confirmam um aumento na ocupação, formalização, diminuição do abandono dos cursos pelos alunos nas universidades, com a menor taxa e com a crescente busca por novas matrículas o EAD está no auge da sua capacidade (Martins, 2020)

\section{Considerações Finais}

Através dessa revisão pôde-se alcançar o objetivo proposto, visto que examinando a literatura ficou evidente que diante o período da pandemia as IES, tiveram que utilizar a tecnologia e inovar no método de ensino. Aperfeiçoando as técnicas de EAD para atender a quantidade elevada de público que passaram a utilizar o ERE.

A forma de comunicação utilizando as vídeo-aulas, palestras online, microlearning, AVA e as bibliotecas virtuais, já faziam parte do EAD, no entanto, após o status de pandemia mesmo as IES que possuíam o método mostraram instabilidades, e complicações de adaptação entre os alunos e docente no ERE.

Em resposta ao questionamento da pesquisa, o estudo mostrou que além da utilização e a adaptação do EAD a inovação com o uso de tecnologia artificial e os smartphones foram o destaque para que o meio de ensino se tornasse mais funcional. Para isso, o fenômeno da internet tem sido fundamental, permitindo que muitas informações ocorram em menos espaço. Por isso são necessários o investimento preventivo de formas distintas do EAD.

Além desses fatores, os formatos móveis têm possibilitado ampliar o conhecimento e a forma de compartilhá-lo e divulgá-lo, principalmente no período atual de pandemia, permitindo uma maior expressão da educação junto ao formato EAD. Foram ultrapassadas as barreiras que impediam o ensino devido à Covid-19, ocorrendo uma transformação da sociedade, o que também ajudou no afastamento social e da forma como as pessoas ampliam seu conhecimento.

Diante a hipótese do estudo, investir em tecnologia se mostrou de fato eficiente. Comparando as universidades que já possuíam um método de EAD, foi mais fácil a adaptação do ERE diante das que precisaram implementar a forma de ensino. 
Ainda em evidência que as escolas públicas que carecem mais do que outras formas de ensino não conseguiram ou tiveram a implantação do EAD de forma falha.

Durante a elaboração desta revisão notou-se que mesmo diante de um tema atual há uma limitação de artigos e informativos sobre o estudo proposto, nota-se que por ser assuntos que foram abordados na pesquisa é realizado de forma diária, os investimentos e tecnologia utilizada no período ERE são descritos superficialmente.

Assim recomenda-se que sejam realizadas pesquisas que mostre em detalhes as mudanças realizadas no ERE e como é aplicado os métodos, na prática.

Em um cenário que sofre constantes mudanças decorrentes de calamidades pública, seja pela necessária modernização e utilização de métodos tecnológicos que contribuem para educação através do Ensino Remoto e Trabalho, e em razão do distanciamento social resultado das altas taxas de transmissão causada pela Covid-19. Sugere-se para trabalhos futuros, estudos e métodos sobre o uso de ferramentas tecnológicas, contudo observando riscos à saúde e segurança dos usuários, e para que não cause distúrbios a saúde mental e psicológica, em razão do uso excessivo dessas tecnologias.

\section{Agradecimentos}

Agradeço minha família pelo apoio e incentivo, especialmente a minha mãe, Ana Maria Martins e a Universidade Federal do Tocantins - UFT Campus Palmas/TO pelas importantes contribuições na discussão para a confecção do trabalho dissertativo, que culminou com a materialização desse artigo.

\section{Referências}

Avelino, W. F.., \& Mendes, J. G. (2020). A realidade da educação brasileira a partir da COVID-19. Boletim De Conjuntura (BOCA), 2(5), 56-62. https://doi.org/10.5281/zenodo.3759679.

Arruda, J. S., \& Siqueira, L. M. R. de C. (2020). Metodologias Ativas, Ensino Híbrido e os Artefatos Digitais: sala de aula em tempos de pandemia. Práticas Educativas, Memórias E Oralidades - Rev. Pemo, 3(1), e314292. https://doi.org/10.47149/pemo.v3i1.4292.

Bezerra, M., Lima, E., Brito, F., \& Santos, A. (2019). Geração Z: relações de uma geração hipertecnológica e o mundo do trabalho. Revista Gestão em Análise, 8(1), 136-149.doi: http://dx.doi.org/10.12662/2359-618xregea.v8i1.p136-149.2019 .

Crub | MEC publica a Portaria 395/20 e prorroga as aulas remotas no sistema federal de ensino superior. (2020, 16 de abril). Crub | Conselho de Reitores das Universidades Brasileiras. https://www.crub.org.br/mec-publica-a-portaria-39520-e-prorroga-as-aulas-remotas-no-sistema-federal-de-ensino-superior/ .

Crub | MEC publica a Portaria 395/20 e prorroga as aulas remotas no sistema federal de ensino superior. (2020, 16 de abril). Crub | Conselho de Reitores das Universidades Brasileiras. https://www.crub.org.br/mec-publica-a-portaria-39520-e-prorroga-as-aulas-remotas-no-sistema-federal-de-ensino-superior/ .

Crub | MEC publica a Portaria 395/20 e prorroga as aulas remotas no sistema federal de ensino superior. (2020, 16 de abril). Crub | Conselho de Reitores das Universidades Brasileiras. https://www.crub.org.br/mec-publica-a-portaria-39520-e-prorroga-as-aulas-remotas-no-sistema-federal-de-ensino-superior/

Crub | MEC publica a Portaria 395/20 e prorroga as aulas remotas no sistema federal de ensino superior. (2020, 16 de abril). Crub | Conselho de Reitores das Universidades Brasileiras. https://www.crub.org.br/mec-publica-a-portaria-39520-e-prorroga-as-aulas-remotas-no-sistema-federal-de-ensino-superior/.

Crub | MEC publica a Portaria 395/20 e prorroga as aulas remotas no sistema federal de ensino superior. (2020, 16 de abril). Crub | Conselho de Reitores das Universidades Brasileiras. https://www.crub.org.br/mec-publica-a-portaria-39520-e-prorroga-as-aulas-remotas-no-sistema-federal-de-ensino-superior/.

Coronavírus Brasil. (2021, 15 de agosto). Coronavírus Brasil. https://covid.saude.gov.br/ .

Camacho, A. C. L. F., Joaquim, F. L., Menezes, H. F. d., \& Sant’ Anna, R. M. (2020). A tutoria na educação à distância em tempos de COVID-19: orientações relevantes. Research, Society and Development, 9(5), Artigo e30953151. https://doi.org/10.33448/rsd-v9i5.3151 .

Castaman, A. S., \& Rodrigues, R. A. (2020). Educação a Distância na crise COVID - 19: um relato de experiência. Research, Society and Development, 9(6), Artigo e180963699. https://doi.org/10.33448/rsd-v9i6.3699.

Educação à distância um marco civilizatório, um olhar holístico da pedagogia: sinergia e reflexões na conectividade em tempos de COVID-19 / Distance education a civilization framework, a holistic view of pedagogy: synergy and reflections in connectivity in COVID-19 times | Churkin | Brazilian Journal of Health Review. (2020, 3 de novembro). Bublicações. https://www.brazilianjournals.com/index.php/BJHR/article/view/8878\#: :text=(2020)\%20\%3E\%20Churkin-

,Educação\%20à\%20distância\%20um\%20marco\%20civilizatório,\%20um\%20olhar\%20holístico\%20da,connectivity\%20in\%20COVID-19\%20times .

Formenton, D., \& Gracioso, L. de S. (2020). Preservação digital: desafios, requisitos, estratégias e produção científica. RDBCI: Revista Digital De Biblioteconomia E Ciência Da Informação, 18(00), e020012. https://doi.org/10.20396/rdbci.v18i0.8659259 . 
Research, Society and Development, v. 11, n. 3, e0711326210, 2022

(CC BY 4.0) | ISSN 2525-3409 | DOI: http://dx.doi.org/10.33448/rsd-v11i3.26210

Hodges, C., Moore, S., Lockee, B., Trust, T., \& Bond, A. (2020). A Diferença entre Ensino Remoto de Emergência e Aprendizagem Online. Revista da Escola, Professor, Educação e Tecnologia, Artigo https://escribo.com/revista/index.php/escola/article/view/17 .

Martins, E. C. (2020). A educação social nos novos espaços e tempos: as realidades entroncadas da intervenção social e educativa. Revista Ibero-Americana De Estudos Em Educação, 15(esp3), 2167-2187. https://doi.org/10.21723/riaee.v15iesp3.14423 .

Mesquita, D., Junior, D. P., \& Gara, E. B. M. (2014). Ambiente virtual de aprendizagem: conceitos, normas, procedimentos e práticas pedagógicas no ensino a distância. Érica.

Oliveira, H. do V. de, \& Souza, F. S. de. (2020). Do Conteúdo Programático ao Sistema de Avaliação: Reflexões Educacionais em Tempos de Pandemia (Covid-19). Boletim de conjuntura (BOCA), 2(5). https://doi.org/10.5281/zenodo.3753654

Pacheco, E. (2020). Desvendando os institutos federais: identidade e objetivos. Educação Profissional E Tecnológica Em Revista,4(1), 4-22. https://doi.org/10.36524/profept.v4i1.575.

Rocha, E. M., \& Lima, J. M. da.S. (2021). Impactos e desafios do ensino on-line decorrentes da pandemia COVID-19. Revista Ibero-Americana De Estudos Em Educação, 16(2), 377-390. https://doi.org/10.21723/riaee.v16i2.14526.

Santos, V. A. V. et al. (2020). O uso das ferramentas digitais no ensino remoto acadêmico: desafios e oportunidades na perspectiva docente. Anais II Congresso nacional de educação. Educação como (re) Existência: mudanças, conscientização e conhecimento., Artigo https://editorarealize.com.br/artigo/visualizar/69166. 